\title{
Creep-fatigue interaction in the AISI H11 tool steel
}

\author{
B. Reggiani ${ }^{1, a}$, M. D'Ascenzo ${ }^{2, b}$, L. Donati ${ }^{1, c}$ \\ J. Zhou ${ }^{2, \mathrm{~d}}$ and L. Tomesani ${ }^{1, \mathrm{e}}$ \\ ${ }^{1}$ University of Bologna, DIEM Department, Viale Risorgimento 2, 40136 Bologna, Italy \\ ${ }^{2}$ Delft University of Technology, Department of Materials Science and Engineering, \\ Mekelweg 2, 2628 CD Delft, The Netherlands \\ a barbara.reggiani@mail.ing.unibo.it, ${ }^{b}$ marco.dascenzo83@gmail.com, ${ }^{c}$ I.donati@unibo.it, \\ 'zhou@tudelft.nl, ${ }^{\mathrm{e}}$ luca.tomesani@unibo.it
}

Keywords: Creep-fatigue interaction; AISI H11 tool steel; Extrusion die; Tool lifetime

\begin{abstract}
The effect of process parameters on the creep-fatigue behavior of a hot-work tool steel for aluminum extrusion die was investigated through a technological test in which the specimen geometry resembled the mandrel of a hollow extrusion die. Tests were performed on a Gleeble thermomechanical simulator by heating the specimen using joule's effect and by applying cyclic loading up to $6.30 \mathrm{~h}$ or till specimen failure. Displacements during the tests at $380,490,540$ and $580^{\circ} \mathrm{C}$ and under the average stresses of 400,600 and $800 \mathrm{MPa}$ were determined. A dwell time of 3 min was introduced during each of the tests to understand the creep behavior. The results showed that the test could indeed physically simulate the cyclic loading on the hollow die during extrusion and reveal all the mechanisms of creep-fatigue interaction.
\end{abstract}

\section{Introduction}

During aluminum extrusion, a severe and complex state of stress acts on the tool system, especially on the die. The load is produced by the ram forcing aluminum to flow through the die at a temperature in a range of $400^{\circ} \mathrm{C}-580^{\circ} \mathrm{C}$. Loading and unloading cycles correspond to repetitive ram strokes at a frequency of 1 to 5 billets every 10 min [1]. Depending on the batch size and die lifetime, up to hundred billets may be consecutively extruded, thus placing the die in the typical low-cycle fatigue regime. The amplitude of the mechanical load on the die is large, varying from zero to a peak value at the beginning of each ram stroke. When a thermal balance of the press is attained after a small number of ram strokes, the die temperature remains fairly stable [2]. Thus, for simplification purpose, the thermal oscillations of the die may be neglected. In addition, the total loading/unloading time for the whole batch and the temperature that the die is exposed to are high enough to consider the creep behavior of the die, particularly for hollow dies. In a hollow die, thin bridges supporting the mandrel, i.e. the part of the die defining the internal shape of the profile, are the most stressed and vulnerable in the die assembly, as these are exposed to the highest process temperature and stress. Hence, the combination of dynamic, heavy loading and high temperature sets a hostile working condition for the mandrel. Premature failure may occur after a certain number of loading/unloading cycles as a result of creep-fatigue interaction.

Many investigations have been carried out to analyze the initiation and propagation of microcracks under creep-fatigue conditions [3-4]. In parallel to experimental investigations, numerical simulations through finite element (FE) calculations have been performed to predict the levels of stress and strain as well as the lifetime of the tools during the extrusion process. It has been acknowledged that the accuracy of the predicted results depends on the ability of the constitutive model to describe the complex thermomechanical behavior of the material. Therefore, the material model is of critical importance. A model suitable for the extrusion die should be capable of dealing with the material damage under creep-fatigue conditions. 
The models available in the literature describing creep-fatigue interaction are formulated in terms of strain, energy or stress. The Manson-Coffin law [5] and the damage parameters proposed by Ostergren and Skelton [6-7] are the most common formulations based on strain and energy, respectively. However, the former has a range of applications limited to small variations of strain and to low temperatures where the creep damage is almost negligible [8]. Moreover, both approaches consider a linear damage accumulation and so does the Wöhler-Miner law formulated in terms of stress and assuming the damage evolution to be a linear function of the number of cycles. Such a condition is however poorly verifiable in experiments. A more comprehensive model based on the internal state variable has been developed by Chaboche et al. [8-9]. It belongs to the unified elasto-viscoplastic models which describe viscoplasticity without separation in time-dependent (creep) and time-independent effects. Despite its ability to describe most of the experimentally observed effects under monotonic or cyclic loadings correctly, the Chaboche model has enjoyed limited popularity, probably due to the perceived complexity of calibrating the material parameters. It is only partially available within the main commercial FE codes.

The development of new technologies for aluminum extrusion aims at a minimum interference between the tool system and the material flow and thus at the optimization of the mechanical performance of the tool that is related both to tool design and tool material. It requires methods capable of fast analysis in order to verify the possible solutions found. The bridges of the mandrel represent the most critical region of the hollow extrusion die and these bridges are indispensible in the extrusion of hollow profiles. A technological test, which allows the analysis to be focused in this region, can help in finding solutions to the problems related to the hollow die and process optimization (e.g. the selection of tool material, the definition of an optimum fillet radius, the assessment of the time-displacement diagram of the mandrel, etc.). The test is desired to cover all the damage mechanisms that the bridges may encounter during aluminum extrusion.

On the basis of the above considerations, a novel testing method for the evaluation of die material and process-related issues were developed. Purposely designed specimens with a shape close to that of the die bridges were tested using a thermomechanical simulator (Gleeble). An experimental campaign at different temperatures and under different loading conditions was undertaken, which allowed the analysis of the correlation of die deformation and lifetime with process parameters in the creep-fatigue regime. In the follow-up research, analytical models available in the literature to describe the material behavior in the creep-fatigue regime will be experimentally validated by using this testing method.

\section{Material and Testing Method}

The material of the specimens investigated in the present study was the hot-work tool steel AISI H11 (or DIN 1.2343, X37CrMoV5-1) with a tempered martensitic structure. Its chemical composition is presented in Table 1. The material was subjected to a four-step heat treatment, typical of that applied to aluminum extrusion dies. It consisted of austenitizing at $1000^{\circ} \mathrm{C}$, quenching in a nitrogen atmosphere and double tempering, which led to a Rockwell hardness value of 46 HRC. The details of the heat treatment are given in Table 2.

Table 1 Chemical composition of the AISI H11 steel used in the present study (in wt. \%)

\begin{tabular}{|c|c|c|c|c|c|c|c|c|c|c|}
\hline $\mathrm{C}$ & $\mathrm{Si}$ & $\mathrm{Mn}$ & $\mathrm{P}$ & $\mathrm{S}$ & $\mathrm{Al}$ & $\mathrm{Cr}$ & $\mathrm{Mo}$ & $\mathrm{Ni}$ & $\mathrm{Cu}$ & $\mathrm{V}$ \\
\hline 0.380 & 1.060 & 0.450 & 0.016 & 0.002 & 0.005 & 4.960 & 1.210 & 0.220 & 0.070 & 0.310 \\
\hline
\end{tabular}

Table 2 Heat treatment applied to the AISI H11 steel

\begin{tabular}{|l|c|c|c|c|}
\hline & Austenitizing & Quenching & First tempering & Second tempering \\
\hline Time & & $30 \mathrm{~min}$ (nitrogen) & $5 \mathrm{~h}$ & $4.5 \mathrm{~h}$ \\
\hline Temperature & $1000^{\circ} \mathrm{C}$ & & $550^{\circ} \mathrm{C}$ & $585^{\circ} \mathrm{C}$ \\
\hline
\end{tabular}


Designed to replicate the geometry of the die mandrel on a smaller scale, the specimens contained a core support and two bridges (Fig. 1). This geometry included all the characteristic elements of a hollow die, including fillet radius, the height and width of the bridges.

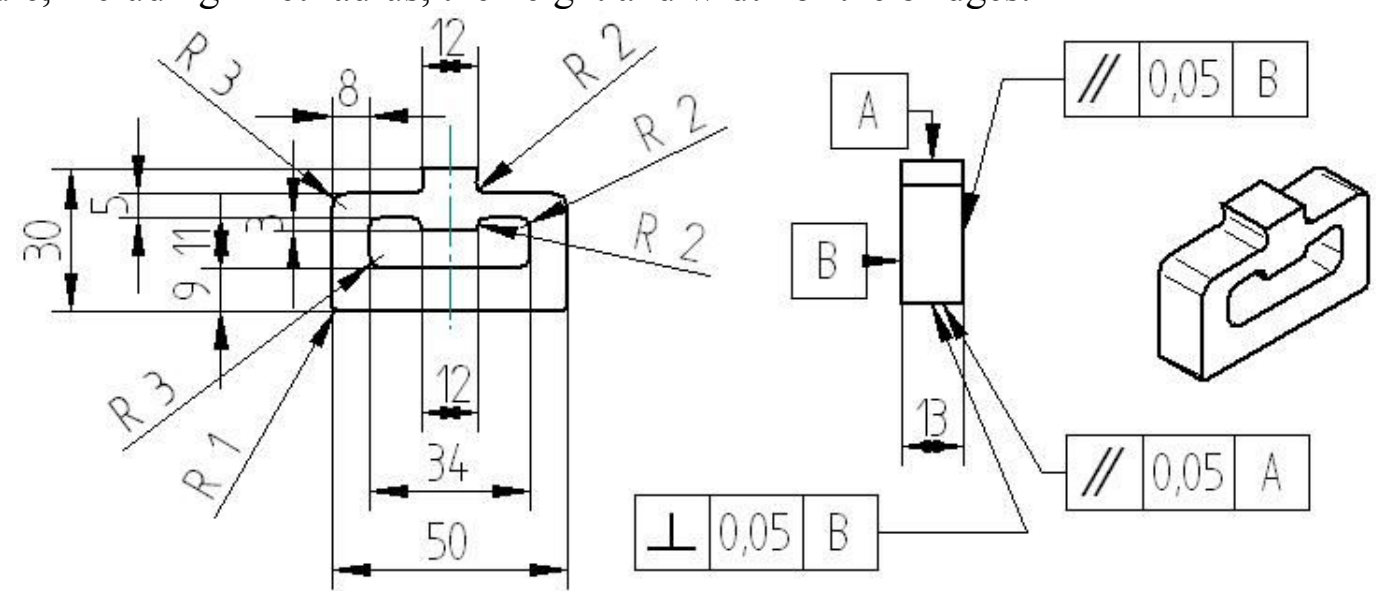

Fig. 1: Geometry and dimensions of the specimen.

FE analysis of the tool-specimen contact and specimen deformation was performed to optimize the specimen geometry and dimensions and to select the load intensities in order to achieve specific average values of stress on the specimen legs $(400,600$ and $800 \mathrm{MPa})$. Fig. 2 shows an average stress of $400 \mathrm{MPa}$ at the specimen legs reached under a particular loading condition.
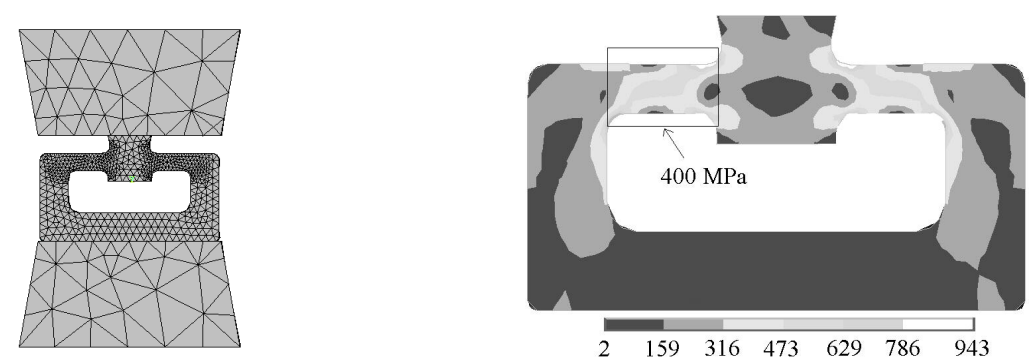

Fig. 2 (left) FE model of the tool-specimen contact and (right) Von Mises stress distribution in the specimen (400 MPa being the average value of the stress in the bridge of the specimen).

During the test, a fully compressive cyclic load was applied to the specimen mandrel and transferred to the bridges, resulting in mostly shear stresses. In order to replicate the loading conditions that occur to the die during the extrusion process, a dwell time (DT) of 3 min was included in the stresscontrolled fatigue loops. The time-history of mechanical waveforms and thermal load is schematically shown in Fig. 3.

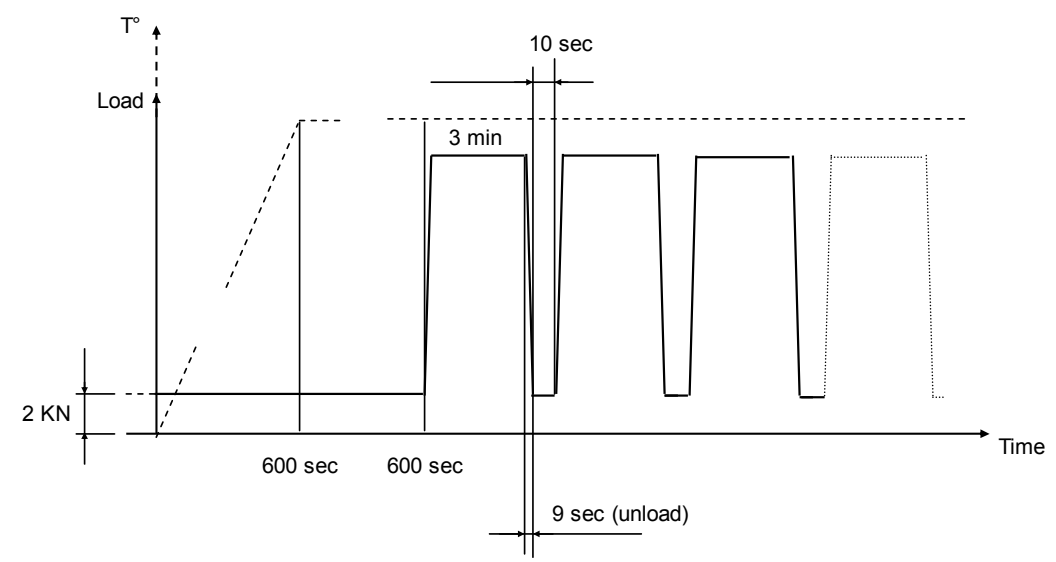

Fig. 3: Mechanical waveforms and thermal load as a function of time. 
The first $600 \mathrm{~s}$ were given to allow the specimen to reach the temperature set, while thermal expansion of the specimen occurred. A minimum compressive load of $2 \mathrm{kN}$ was maintained during the test in order to keep the specimen on hold between the tools. The tools were made of the same steel as the specimen and had a hardness value of 55 HRC. Four temperatures (380, 490, 540 and $\left.580{ }^{\circ} \mathrm{C}\right)$ and three levels of stress $(400,600$ and $800 \mathrm{MPa}$ which were the average values of the Von Mises stress at the bridge area of the specimen) were applied to cover the thermomechanical conditions that the mandrel of a hollow die may encounter in extrusion practice.

A servo-hydraulic thermomechanical simulator, Gleeble-1500D, was used for the tests (Fig. 4). The specimen was heated using Joule's effect, with a close-loop feedback signal enabling precise control of the heat input throughout the test. Two thermocouples were spot-welded on the surface of the specimen, one for regulating heating in order to maintain the preset temperature during the test and another for additional monitoring. The displacements of the anvils were registered throughout the test. All the tests were terminated after $6.30 \mathrm{~h}$, corresponding to 106 loading cycles, unless the specimen broke prematurely. After unloading and cooling down to room temperature, the final height of the specimen was measured to obtain the data of its final permanent deformation.

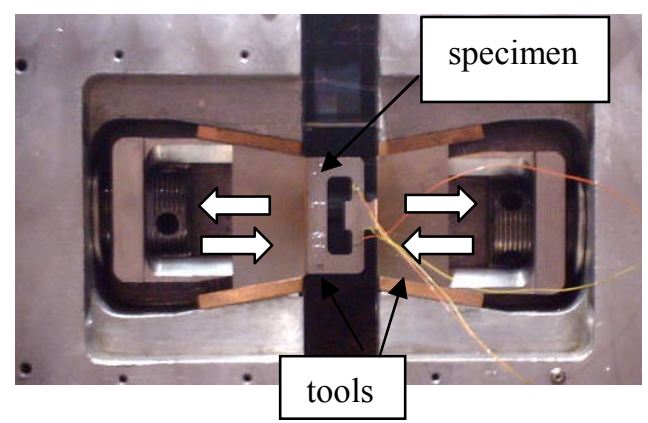

Fig. 4: Specimen placed in the Gleeble 1500D thermomechanical simulator.

To ascertain the thermal stability of the specimen during the test and determine the temperature distribution, two additional tests were performed during which the temperatures at 15 points distributed all over the specimen surfaces were monitored.

The thermophysical properties of the AISI H11 tool steel as a function of temperature are reported in [10]. Accurate determination of displacement during the test was considered very important. As the displacement transducer is located at the end of the loading system of the Gleeble machine, the measurement is the sum of various contributions including those from the specimen, the hydraulic loading system, anvils, etc. In order to quantify the yielding of the Gleeble system, a block of material, assumed to be rigid, was placed between the tools. The displacement under the static compressive loads corresponding to 400,600 and $800 \mathrm{MPa}$ in the bridges of the specimen was taken as that of the Gleeble system.

\section{Results and Discussion}

The insertion of one or two copper plates between the tool and specimen was found to be a workable solution to the stabilization of the specimen temperature during the test. Fig. $5 \mathrm{c}$ shows the temperature distribution at the 15 measurement points on the specimen (Fig. 5a). The evolutions of these temperatures over a period of time are presented in Fig. 5b which clearly shows the stability of the temperatures after $600 \mathrm{~s}$. The differences in temperature between the two sides of the specimen at the mirror points (2-12, 1-11 and 3-13) were noticed. The maximum difference was $33^{\circ} \mathrm{C}$ between points 2 and 12 . This was attributed mainly to the imperfect contact at the specimen-copper plates-tool interfaces. The temperature non-uniformity was thought to be acceptable, considering the accuracy of the thermocouple measurements $\left( \pm 6^{\circ} \mathrm{C}\right)$. 

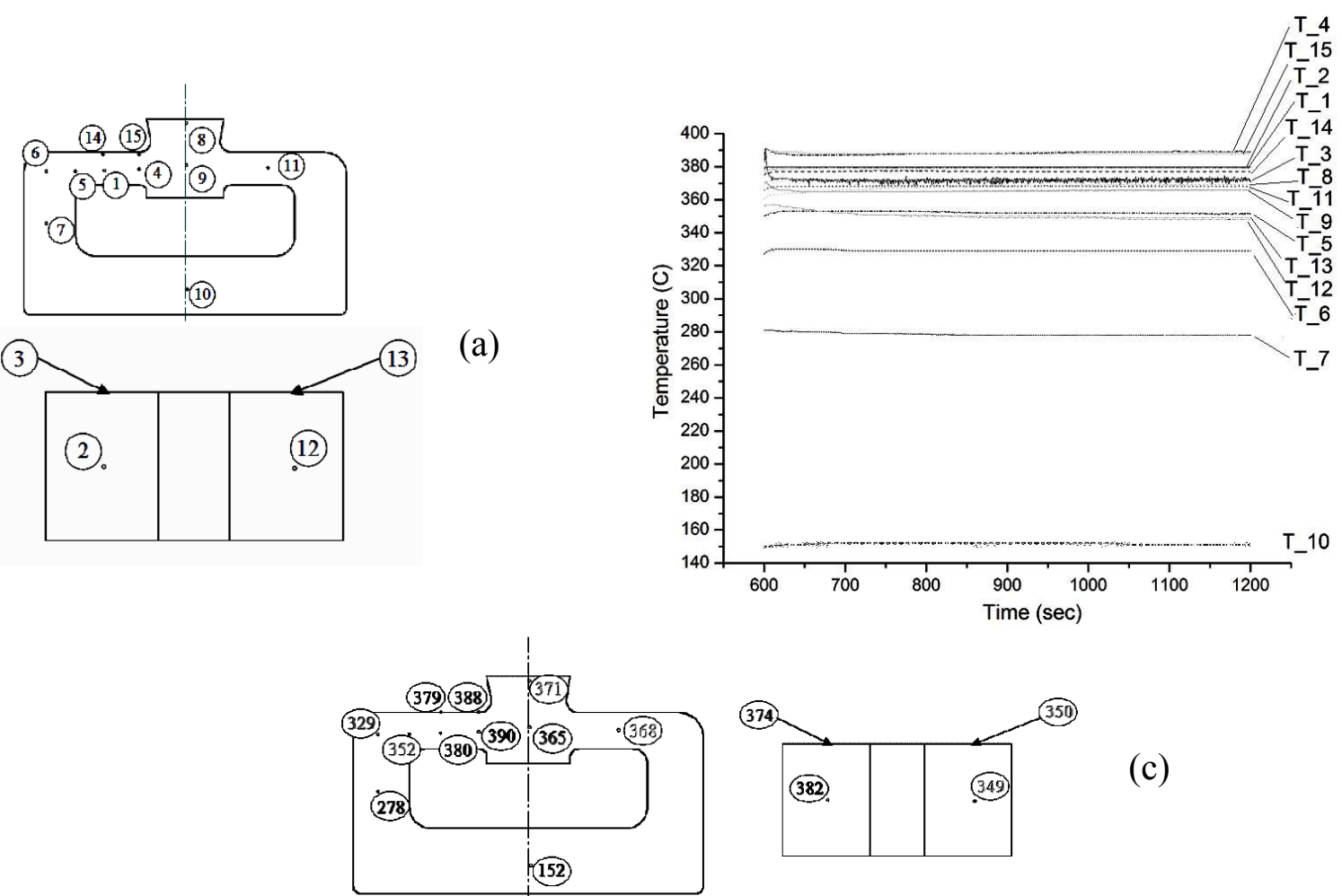

(c)

Fig. 5 (a) Positions of the 15 measurement points on the specimen to check the temperature distribution, (b) evolution of the temperatures over time and (c) temperature distribution on the specimen at a set temperature of $380^{\circ} \mathrm{C}$.

Table 3 Experimental results obtained from the creep-fatigue tests at each of the temperatures and stresses $\left(\sigma_{\mathrm{AVM}}\right)$ in the form of the time (sec-x axis)-stroke (mm-y axis) diagram. In The diagrams have the same scale except those of the tests at (i) $490^{\circ} \mathrm{C}$ and $800 \mathrm{MPa}$, (ii) $540^{\circ} \mathrm{C}$ and $800 \mathrm{MPa}$, (iii) $580^{\circ} \mathrm{C}$ and $600 \mathrm{MPa}$ and (iv) $580^{\circ} \mathrm{C}$ and $800 \mathrm{MPa}$.

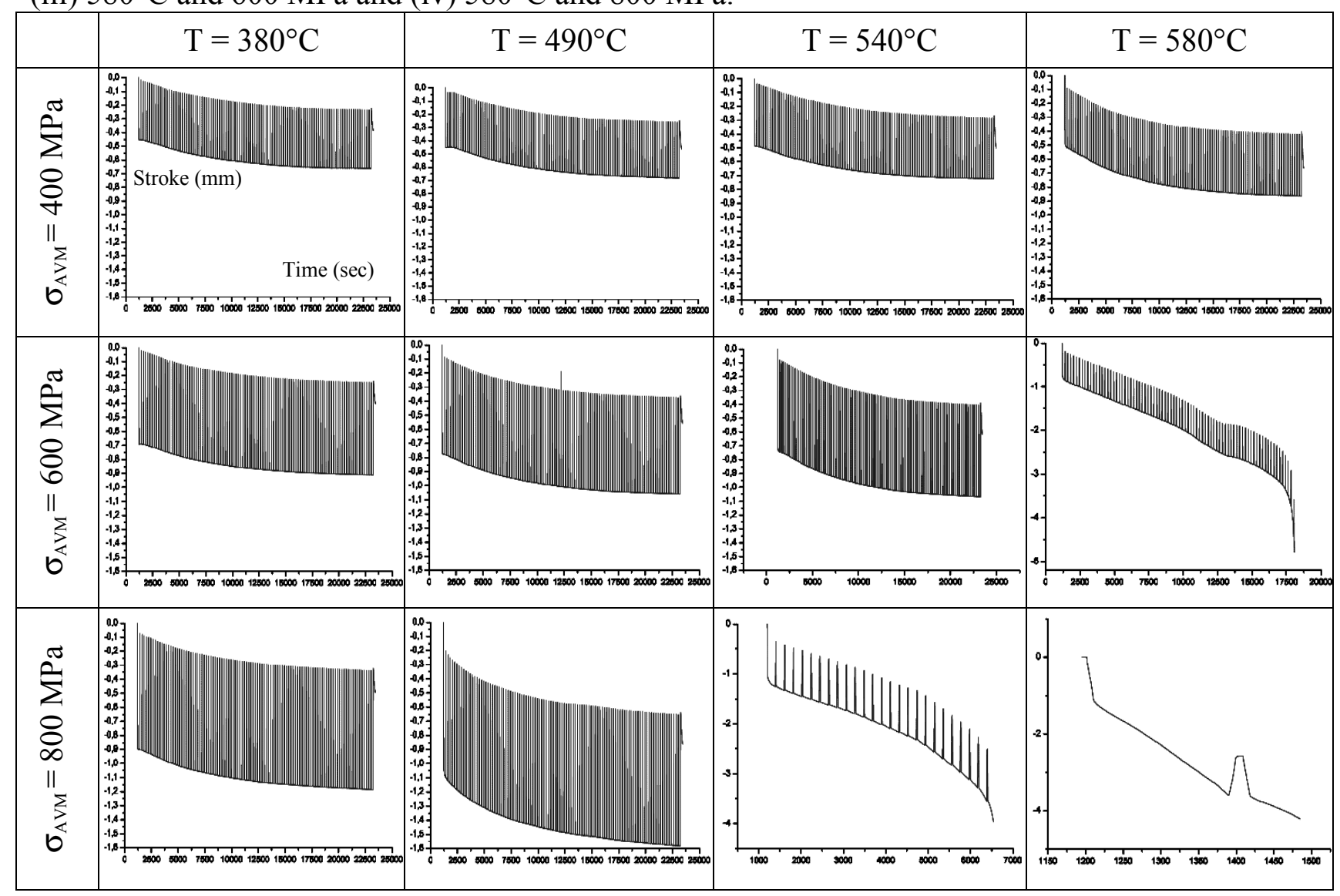


In Table 3, the results of the creep-fatigue tests performed are shown in the form of the timedisplacement diagram. The tests at $800 \mathrm{MPa}$ and $540^{\circ} \mathrm{C}$ and those at $580^{\circ} \mathrm{C}$ were ended after $1.8 \mathrm{~h}$ and $0.5 \mathrm{~h}$, respectively, due to the failure of the specimens. In Table 4, the values of the final permanent deformation of the specimens after 106 loading cycles and cooling, measured by means of a caliper, are reported. These measurements had an uncertainty of $\pm 0.05 \mathrm{~mm}$.

Table 4 Final permanent deformation of the specimens after unloading and at room temperature

\begin{tabular}{|l|ccccc|}
\hline & $\mathrm{T}=380^{\circ} \mathrm{C}$ & $\mathrm{T}=490^{\circ} \mathrm{C}$ & $\mathrm{T}=540^{\circ} \mathrm{C}$ & $\mathrm{T}=580^{\circ} \mathrm{C}$ \\
\cline { 1 - 1 } $400 \mathrm{MPa}$ & 0.01 & 0.01 & 0.06 & 0.13 \\
\cline { 1 - 1 } $600 \mathrm{MPa}$ & 0.04 & 0.02 & 0.11 & fracture $\left(83^{\text {rd }}\right.$ cycle $)$ \\
\cline { 1 - 1 } $800 \mathrm{MPa}$ & 0.06 & 0.34 & Fracture $\left(25^{\text {th }}\right.$ cycle $)$ & fracture $\left(1^{\text {st }}\right.$ cycle $)$ \\
\hline
\end{tabular}

The yielding of the Gleeble system under the static compressive loads of 400, 600 and $800 \mathrm{MPa}$ in the bridges of the specimen is reported in Table 5. It is indeed reasonable to assume a constant yielding of the system over the test duration, even when the deformation of the copper plates is taken into consideration. (Note the small thickness of the copper plates $(0.5 \mathrm{~mm})$ relative to the whole system.)

Table 5 Displacements due to the Gleeble system yielding $(\mathrm{mm})$

\begin{tabular}{|l|c|c|c|}
\hline & $400 \mathrm{MPa}$ & $600 \mathrm{MPa}$ & $800 \mathrm{MPa}$ \\
\hline 1 copper plate & -0.370 & -0.560 & -0.705 \\
\hline 2 copper plate & -0.380 & -0.570 & -0.720 \\
\hline
\end{tabular}

The displacements of the specimens at the first, tenth, sixtieth and hundredth cycle, after the effect of the Gleeble machine yielding has been accounted for, are reported in Table 6 . The displacements during the dwell time (in the middle and at the end of the dwell time, i.e. 1.5DT and 3.0DT, respectively) are also reported in Table 6 to show the creep behaviour (Fig. 6). The displacement in the last row of Table 6 was registered at the last cycle (the $106^{\text {th }}$ ) with the load applied and at the corresponding temperature.

Table 6 Displacement of the specimen due to deformation during the creep-fatigue tests

\begin{tabular}{|c|c|c|c|c|c|c|c|c|c|c|c|c|}
\hline & \multicolumn{3}{|c|}{$380^{\circ} \mathrm{C}$} & \multicolumn{3}{|c|}{$490^{\circ} \mathrm{C}$} & \multicolumn{3}{|c|}{$540^{\circ} \mathrm{C}$} & \multicolumn{3}{|c|}{$580^{\circ} \mathrm{C}$} \\
\hline cycle & 400 & 600 & 800 & 400 & 600 & 800 & 400 & 600 & 800 & 400 & 600 & 800 \\
\hline $1^{\text {st }}\left(\mathrm{u}_{1}\right)$ & -0.080 & -0.125 & -0.166 & -0.063 & -0.188 & -0.283 & -0.095 & -0.136 & -0.300 & -0.105 & -0.168 & -0.407 \\
\hline $1.5 \mathrm{DT}$ & -0.082 & -0.129 & -0.180 & -0.070 & -0.205 & -0.362 & -0.109 & -0.169 & -0.483 & -0.140 & -0.263 & -1.593 \\
\hline $3.0 \mathrm{DT}$ & -0.080 & -0.125 & -0.174 & -0.067 & -0.202 & -0.374 & -0.108 & -0.170 & -0.538 & -0.146 & -0.290 & -2.894 \\
\hline $10^{\mathrm{st}}$ & -0.113 & -0.156 & -0.224 & $\begin{array}{c}-0.094 \\
\end{array}$ & -0.246 & $\begin{array}{c}-0.480 \\
\end{array}$ & $\begin{array}{l}-0.137 \\
\end{array}$ & -0.211 & -0.986 & -0.205 & -0.497 & \\
\hline $1.5 \mathrm{DT}$ & -0.121 & -0.170 & -0.239 & -0.104 & -0.267 & -0.508 & -0.153 & -0.232 & -1.045 & -0.223 & -0.536 & \\
\hline $3.0 \mathrm{DT}$ & -0.121 & -0.170 & -0.235 & -0.103 & -0.268 & -0.507 & -0.155 & -0.232 & -1.072 & -0.226 & -0.547 & \\
\hline $60^{\text {st }}$ & -0.256 & $\begin{array}{l}-0.308 \\
\end{array}$ & -0.407 & -0.257 & -0.437 & -0.763 & -0.301 & -0.434 & & $\begin{array}{l}-0.434 \\
\end{array}$ & -1.880 & \\
\hline $1.5 \mathrm{DT}$ & -0.257 & -0.310 & -0.408 & -0.258 & -0.438 & -0.767 & -0.302 & -0.437 & & -0.437 & -1.899 & \\
\hline 3.0DT & -0.259 & -0.310 & -0.409 & -0.259 & -0.439 & -0.765 & -0.302 & -0.436 & & -0.435 & -1.906 & \\
\hline $100^{\mathrm{st}}$ & -0.292 & -0.347 & -0.459 & -0.298 & -0.483 & -0.843 & -0.338 & -0.489 & & -0.482 & & \\
\hline $1.5 \mathrm{DT}$ & -0.291 & -0.349 & -0.461 & -0.299 & -0.486 & -0.855 & -0.343 & -0.493 & & -0.492 & & \\
\hline $3.0 \mathrm{DT}$ & -0.288 & -0.347 & -0.458 & -0.296 & -0.482 & -0.852 & -0.339 & -0.487 & & -0.489 & & \\
\hline Displacement* & -0.291 & -0.346 & -0.459 & -0.299 & -0.480 & -0.843 & -0.336 & -0.489 & & -0.483 & & \\
\hline$\overline{0} \% e^{* *}$ & 0.702 & 0.737 & 0.977 & 0.786 & 0.973 & 1.868 & 0.805 & 1.179 & 2.575 & 1.260 & 5.793 & 8.290 \\
\hline
\end{tabular}

* measured with the load applied and at the corresponding temperature

** deformation in percentage calculated as the ratio of $\left(\mathrm{u}_{\mathrm{f}}-\mathrm{u}_{1}\right)$ to the specimen height $(30 \mathrm{~mm})$ 

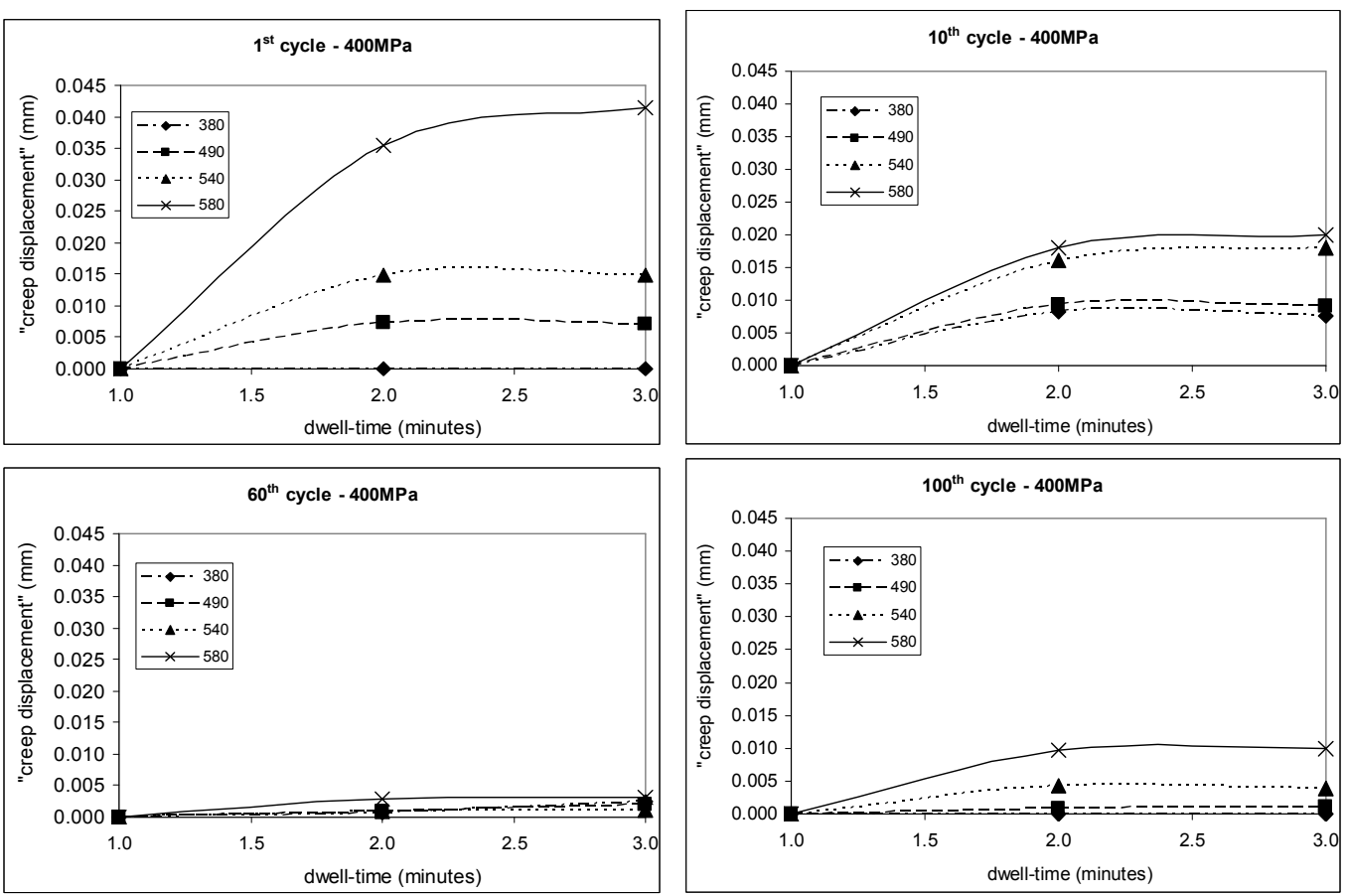

Fig. 6 Displacements occurring during the dwell-time with a stress of $400 \mathrm{MPa}$ released, at the four temperatures and at (a) first, (b) tenth, (c) sixtieth and (d) hundredth cycle.

From Tables 3 and 6, a progressive increment of the displacement rate from the first to the last cycle was observed. The increment became greater as the level of stress increased (e.g. from $0.702 \mathrm{~mm}$ to $0.977 \mathrm{~mm}$ at $380^{\circ}$ ) and as the temperature rose (e.g. from $0.702 \mathrm{~mm}$ to $1.260 \mathrm{~mm}$ at $400 \mathrm{MPa}$ ).

Velay, Bernhart et al. investigated the cyclic behavior of tempered martensitic hot-work tool steels with particular reference to the AISI H11 tool steel [10-12]. Cyclic softening of the material was observed, which could be divided into three stages: an initial strong softening followed by a slow steady softening that took the major part of the material life, and finally a drastic softening driven by crack propagation. In the present research, the first two stages of the cyclic softening were captured during almost all of the tests performed (Table 3) in which a change in the slope of the timedisplacement history occurred. This behavior became more remarked at a higher level of stress and/or at a higher temperature (i.e., $800 \mathrm{MPa}$ and $490^{\circ} \mathrm{C}$, or $400 \mathrm{MPa}$ and $580^{\circ} \mathrm{C}$ ). Indeed, the rate of stress softening increased as the test temperature and stress intensity increased. The second and third stages of the cyclic softening were detected at the most critical test conditions of both parameters $\left(600 \mathrm{MPa} / 580^{\circ} \mathrm{C}, 800 \mathrm{MPa} / 540^{\circ} \mathrm{C}, 800 \mathrm{MPa} / 580^{\circ} \mathrm{C}\right)$ that lead to a premature failure of the specimens.

As can be seen in Fig. 6, the presence of a dwell-time of 3 min introduced a time-dependent effect on the specimen deformation. Such a time-dependent effect (material viscosity) produced an increased displacement, which could be explained by the additional inelastic strain, as described in [8]. Indeed, the viscoplastic strain had the time to develop, resulting in an enlarging hysteresis loop. The path of the displacement over the dwell time suggested that a primary as well as a secondary creep phase took place during this time. Moreover, the stabilization of the creep displacement during the dwell time from the first to the sixtieth cycle, as shown in Fig. 6, confirmed the presence of slow steady stage of the softening (Fig. 6c).

\section{Summary}

Previous research has shown that creep plays a fundamental role in resulting in deformation even during short cycles. Thus, hot-work steels used for extrusion tools should be evaluated with respect not only to their hot strength but also to their time-dependant creep strength. The latter is also of 
importance in the creep-fatigue interaction regime. With this in mind, the present research was performed to investigate the performance of a hot-work tool steel H11 under the normal working conditions as applied to hollow extrusion dies in industrial practice. The purposely designed specimens were tested under creep-fatigue loading, e.g. low-cycle fatigue with a dwell-time at different levels of stress and at different temperatures. The resulting evolution of the displacements indicated a mixed time- and cycle-dependant damage mechanism; at a high temperature, the cycling loading led to the softening of the material which was accelerated by the superimposed creep.

The results of the present research confirmed the capabilities of the testing method to evaluate the effects of both the design (stress) and process (temperature) parameters in extrusion on the deformation and lifetime of the mandrel in the hollow die. The geometry of the specimen designed on the basis of FE analysis allowed the dedicated analysis of the regions affected by creep and fatigue. This made the test a powerful tool for the die designer.

\section{Acknowledgments}

The authors would like to thank COMPES S.p.A. for providing the tool material and specimens and Mr. A.R. Eivani and Mr. J.M. Hofman for their assistance during the tests.

\section{References}

[1] L. Donati and L. Tomesani: J. Mat. Process. Technol., Vol. 164-165 (2005), p.1025.

[2] A. Assaad, H.J.M. Geijselaers and J. Huétink, in: Proc. of Int. Deep Drawing Research Group Conference (IDDRG 2008), Olofstrom, Sweden (2008).

[3] J. Granacher, T.S. Mao, K. Maile and R. Fisher: Mater. High. Temp. Vol. 15 (1998), p. 289.

[4] D.J. Michel and A.W. Thomson: Fatigue Vol. 87 (1987), 1057.

[5] L. Coffin, in: Fracture, Vol. 1, ICF4, Waterloo, Ontario, Canada (1977), p. 263.

[6] W. Ostergren: J. Test. Eval. Vol. 4 (1976), p. 327.

[7] R. Skelton: Mater. Sci. Technol. Vol. 7 (1981), p. 427.

[8] J. Lemaitre and J.L. Chaboche: Mechanics of Solid Materials (Cambridge University Press, Cambridge, U.K. 1990).

[9] J.L. Chaboche: Int. J. Plast. Vol. 5 (1989), p. 247.

[10]Z. Ahmer, V. Velay, G. Bernhart and F. Rezai-Aria: Int. J. Microstruct. Mater. Prop. Vol. 3 (2008), p. 326.

[11]Z. Zhang, D. Delagne and G. Bernhart: Int. J. Fatigue Vol. 24 (2002), p. 635.

[12]V. Velay, G. Bernhart, D. Delagnes and L. Penazzi: Fatigue Fract. Eng. Mater. Struct. Vol. 28 (2005), p. 1023. 